\title{
An Empirical Study on the Influencing Factors of Tourists' Cultural Tourism Decision-Making
}

\author{
Yu-fei ZHANG ${ }^{1}$ and Hui-ying $\mathrm{CHEN}^{2, *}$ \\ ${ }^{1}$ Wuhan Polytechnic University, Grade 15, Culture Industry Management Wuhan Polytechnic \\ University, Wuhan, Hubei, 430023, China \\ ${ }^{2}$ School of Arts and Communications, Wuhan Polytechnic University, Wuhan, Hubei, 430023, China \\ ${ }^{*}$ Corresponding author
}

Keywords: Tourist decision making, Culture-oriented travel, Influencing factor.

\begin{abstract}
A total of 500 tourists with cultural tourism experience or motivation were investigated, of which 466 were valid. Using SPSS 19.0, the factors Pearson correlation and regression analysis were carried out on the data collected from the questionnaire. The results showed that tourist's cultural tourism decision was influenced by five factors: publicity, price level, cultural connotation, environment atmosphere and emotional demand. And these five factors have significant correlation with tourists' cultural tourism decision-making. Only by strengthening the propaganda and promotion of cultural tourism, excavating and promoting the cultural connotation of cultural tourism scenic spots, creating a good atmosphere of cultural tourism environment and perfecting the price forming mechanism of cultural tourism market, can the quality of cultural tourism decision-making be improved.
\end{abstract}

\section{Introduction}

For modern tourists, tourism is no longer just a kind of material enjoyment, more important is to meet the higher level of spiritual needs.Cultural tourism takes culture as its soul and tourism as its carrier. It is rich in connotation and diverse in forms. It is favored by tourists and has great prospects for development.The report of the 18 National Congress of the Communist Party of China put forward the strategic tasks of "building a socialist cultural power" and "developing cultural tourism in depth." the guidelines and policies in the outline of the 13th Five-Year Plan for Tourism also pointed out. Through the integration of cultural industry and tourism industry, "cultural tourism", the traditional "ticket economy" is replaced by the operation of creative tourism industrialization, which makes the development prospect of cultural tourism more broad.

\section{Research and Design}

In the representative places of cultural tourism destinations in Wuhan (such as Yellow Crane Tower, Red Tower, Guayuan Temple, etc.), the author randomly distributed questionnaires and interviews to tourists who had cultural tourism experience or had inner cultural tourism motivation and demand. On the basis of literature review and interview, the questionnaire determines five most representative factors, which are propaganda promotion, price level, cultural connotation, etc. The environmental atmosphere and emotional needs form the initial question items of tourist's cultural tourism decision making, there are 22 items. Among them, there are 4 factors of propaganda and promotion, 4 factors of price level, 5 items of cultural connotation, 5 items of environment and atmosphere, 4 items of emotional demand. See Table 1. 
Table 1. Explanation of the sources of each question item in the questionnaire on the influencing factors of tourist Cultural Tourism

\begin{tabular}{|c|c|c|}
\hline Dimension & $\begin{array}{l}\text { Question item } \\
\end{array}$ & Question source \\
\hline \multirow{4}{*}{$\begin{array}{c}\text { Publicity } \\
\text { and } \\
\text { promotion }\end{array}$} & $\begin{array}{l}\text { The influence of word-of-mouth recommendation of people around } \\
\text { you on your cultural tourism decisions }\end{array}$ & Zalatan,A. ( 1998 ) \\
\hline & $\begin{array}{l}\text { The influence of Advertising in Cultural Tourism Scenic spots on your } \\
\text { Cultural Tourism decision }\end{array}$ & \multirow{2}{*}{$\begin{array}{l}\text { Wang Jiaochen } \\
\text { (2001) }\end{array}$} \\
\hline & $\begin{array}{l}\text { The influence of Travel Agency's Marketing and Promotion on your } \\
\text { Cultural Tourism decision }\end{array}$ & \\
\hline & $\begin{array}{l}\text { The influence of Internet, TV, and other New and Old Media publicity } \\
\text { on your Cultural Tourism decision }\end{array}$ & Summary and induction \\
\hline \multirow{4}{*}{ price level } & $\begin{array}{l}\text { The influence of Commodity consumption Price in tourist destination } \\
\text { on your Cultural Tourism Decision-Making }\end{array}$ & Brown, T. ( 2001 ) \\
\hline & $\begin{array}{l}\text { The influence of Food and accommodation Price level of tourist } \\
\text { destination on your Cultural Tourism Decision-Making }\end{array}$ & Hyunjung $\operatorname{Im}(2011)$ \\
\hline & $\begin{array}{l}\text { The influence of ticket Price level of tourist destination on your } \\
\text { Cultural Tourism Decision-Making }\end{array}$ & Interview results \\
\hline & $\begin{array}{l}\text { The impact of the Transportation cost on your Cultural Tourism } \\
\text { Decision-Making }\end{array}$ & Du Jiang (2003) \\
\hline \multirow{6}{*}{$\begin{array}{l}\text { Cultural } \\
\text { connotation }\end{array}$} & $\begin{array}{l}\text { The influence of the Cultural connotation difference of tourist } \\
\text { destination on your Cultural Tourism Decision-Making }\end{array}$ & Ren Guanwen (2008) \\
\hline & $\begin{array}{l}\text { The influence of the religious Culture of the tourist destination on your } \\
\text { Cultural Tourism Decision-Making }\end{array}$ & Hu Benchun (2014) \\
\hline & $\begin{array}{l}\text { The influence of the Architectural style and characteristic degree of } \\
\text { tourist destination on your Cultural Tourism Decision-Making }\end{array}$ & Summary and induction \\
\hline & $\begin{array}{l}\text { The influence of the Historical change and Development of tourist } \\
\text { destination on your Cultural Tourism decision }\end{array}$ & \\
\hline & $\begin{array}{l}\text { The influence of the Brand effect of Tourism products on your } \\
\text { Cultural Tourism Decision-Making }\end{array}$ & $\begin{array}{l}\text { Mr Lau Yung-ching } \\
\text { (2009) }\end{array}$ \\
\hline & The influence of Local folklore on your Cultural Tourism decision & Jin Guangsheng (2014) \\
\hline \multirow{4}{*}{$\begin{array}{l}\text { Environmental } \\
\text { atmosphere }\end{array}$} & $\begin{array}{l}\text { The influence of quiet and relaxed atmosphere of tourist destination on } \\
\text { your Cultural Tourism decision }\end{array}$ & Hyunjung $\operatorname{Im}(2011)$ \\
\hline & $\begin{array}{l}\text { The influence of the overall Cultural atmosphere of the tourist } \\
\text { destination on your Cultural Tourism Decision-Making }\end{array}$ & Ren Guanwen (2008) \\
\hline & $\begin{array}{l}\text { The influence of neat and Beautiful Environment of tourist destination } \\
\text { on your Cultural Tourism Decision-Making }\end{array}$ & \multirow{2}{*}{ Interview results } \\
\hline & $\begin{array}{l}\text { The influence of working attitude and Service level of tourist } \\
\text { destination on your Cultural Tourism Decision-making }\end{array}$ & \\
\hline \multirow{4}{*}{ affection need } & Cultural tourism can make me happy. & Mr Lau Hong-yan (2005) \\
\hline & $\begin{array}{l}\text { Cultural tourism can promote the expansion of my knowledge and } \\
\text { knowledge. }\end{array}$ & $\begin{array}{l}\text { Mengji Jun, Cui Fengjun } \\
\text { 2000) }\end{array}$ \\
\hline & Cultural tourism enables me to experience culture and enrich myself & \multirow{2}{*}{ Ren Guanwen (2008) } \\
\hline & Cultural tourism can satisfy my pursuit of original and original culture. & \\
\hline
\end{tabular}

In accordance with the norms of the questionnaire survey, 100 tourists of different ages, different academic qualifications and different occupations were selected to carry out the pre-questionnaire test, of which 96 were valid. The results showed that the question items were set reasonably and effectively. Then the questionnaire was distributed in a large scale.Two kinds of questionnaire models of network and entity were adopted: 150 questionnaires were completed through the network platform of questionnaire star, 144 valid questionnaires were collected, 350 questionnaires were distributed on the spot, 322 effective questionnaires were recovered.The total number of questionnaires issued was 500, of which 34 were invalid. 466 valid questionnaires were finally recovered, with an effective recovery rate of 93.20.In general, the effective recovery rate of the questionnaire is in accordance with the requirements of the survey standard, and the results are true and effective. 


\section{Data Analysis and Results}

\section{Reliability Analysis}

Reliability refers to the credibility of investigation and analysis. In the process of empirical research, reliability analysis is a necessary step for subsequent analysis. The data obtained from the questionnaire must be preliminarily tested for further in-depth study. In this study, the reliability of the questionnaire is tested by the internal consistency of the estimated data. The Cronbach coefficient is mainly used to estimate the correlation between the Cronbach coefficient and the variables and the internal consistency.For unverified variables, the Cronbach coefficient is acceptable only if it is greater than 0. 6 .

Questionnaire Overall Reliability Analysis. A shown in Table 2, the reliability of the questionnaire as a whole is analyzed. The Cronbach's Alphsa coefficient of the standardized item is 0.862 , which indicates that the internal consistency among the variables in the questionnaire is better, and the correlation between the variables is strong. The data collected by the questionnaire have high reliability.

Table 2. Overall reliability analysis results

\begin{tabular}{|c|c|c|c|}
\hline Item dimension & Cronbach's Alpha & $\begin{array}{c}\text { Cronbachs Alpha based } \\
\text { on standardized terms }\end{array}$ & Number of terms \\
\hline Questionnaire as a whole & 0.861 & 0.862 & 25 \\
\hline
\end{tabular}

Reliability Analysis of Variables. As shown in Table 3, each variable is more than 0.6 based on the standardized Cronbach's Alpha coefficient, which indicates that the degree of internal consistency of each variable is high, that is, the reliability of each variable in this study is acceptable.

Table 3. Reliability analysis results of each variable

\begin{tabular}{|c|c|c|c|}
\hline variable & $\begin{array}{c}\text { Cronbach's } \\
\text { Alpha }\end{array}$ & $\begin{array}{c}\text { Cronbachs Alpha based } \\
\text { on standardized terms }\end{array}$ & Number of terms \\
\hline Publicity and promotion & 0.692 & 0.691 & 4 \\
\hline Price level & 0.789 & 0.789 & 4 \\
\hline Cultural connotation & 0.732 & 0.731 & 5 \\
\hline $\begin{array}{c}\text { Environmental } \\
\text { atmosphere }\end{array}$ & 0.616 & 0.619 & 5 \\
\hline Affection need & 0.694 & 0.693 & 3 \\
\hline Cultural tourism decision & 0.731 & 0.731 & 4 \\
\hline
\end{tabular}

\section{Factor Analysis}

In this study, a few main variables can be obtained by factor analysis of the results of the questionnaire by SPSS software, and then the main characteristics of the original variables can be represented by these main variables.

Validity Test. The premise of factor analysis is that the initial variables are highly correlated, because without strong correlation, the factors that reflect commonality cannot be extracted from them. Therefore, the validity test of initial variables is also a necessary preparation step before factor analysis.As shown in Table 4, the KMO test value in this study is 0.812 , and the significant probability of sphericity test greater than 0.8 Bartlett is 0.000 , less than 0.01 , which indicates that the correlation coefficient in the sample is significantly different from the unit matrix. To sum up, this study is suitable for factor analysis.

Table 4. Sphericity test of KMO and Bartlett

\begin{tabular}{|c|c|c|}
\hline \multicolumn{2}{|c|}{ Kaiser-Meyer-Olkin measure of sampling adequacy } & 0.812 \\
\hline \multirow{2}{*}{ Sphericity Test of Bartlett } & Approximate chi-square & 1312.427 \\
\cline { 2 - 3 } & df & 231 \\
\cline { 2 - 3 } & Sig. & 0.000 \\
\hline
\end{tabular}


Factor Analysis of Independent Variables. The main purpose of factor analysis in this study is to reduce the dimension. The factors whose load is greater than 0.5 are extracted by Varimax orthogonal transformation method. Therefore, which variables can explain most of the information of all variables in the factors that affect tourist cultural tourism decision. Through Varimax orthogonal transformation of the data, 5 factors are extracted from 22 items through the characteristic root being greater than 1 . These five factors can explain the variance of total variance 64.478.The factor load of each item is greater than 0.5 , which indicates that the data meet the requirements of the research. Therefore, the five factors generated are named: factor 1 is propagandizing and popularizing. Factor 2 is price level, factor 3 is cultural connotation, factor 4 is environmental atmosphere, factor 5 is emotional demand.

Table 5. Factor load table after rotation of independent variables

\begin{tabular}{|c|c|c|c|c|c|}
\hline \multirow{2}{*}{ Subject item } & \multicolumn{5}{|c|}{ ingredient } \\
\hline & 1 & 2 & 3 & 4 & 5 \\
\hline Promotion 1 & 0.633 & 0.055 & 0.133 & 0.124 & -0.148 \\
\hline Promotion 2 & 0.619 & 0.160 & 0.284 & 0.091 & 0.218 \\
\hline Promotion 3 & 0.761 & 0.156 & 0.143 & 0.055 & -0.046 \\
\hline Promotion 4 & 0.514 & 0.135 & 0.191 & 0.143 & 0.179 \\
\hline Price level 1 & 0.096 & 0.752 & 0.131 & 0.045 & -0.013 \\
\hline Price level 2 & 0.066 & 0.773 & 0.077 & -0.059 & 0.094 \\
\hline Price level 3 & 0.129 & 0.847 & 0.011 & -0.022 & 0.027 \\
\hline Price level 4 & -0.031 & 0.635 & 0.329 & -0.003 & 0.141 \\
\hline Cultural connotations 1 & -0.076 & 0.232 & 0.551 & 0.312 & -0.067 \\
\hline Cultural connotations 2 & 0.191 & 0.167 & 0.671 & -0.073 & -0.137 \\
\hline Cultural connotations 3 & 0.036 & -0.046 & 0.679 & 0.313 & 0.134 \\
\hline Cultural connotations 4 & 0.089 & -0.162 & 0.773 & 0.146 & -0.053 \\
\hline Cultural connotations 5 & 0.248 & 0.205 & 0.523 & -0.110 & 0.219 \\
\hline $\begin{array}{c}\text { Environmental } \\
\text { atmosphere } 1 \\
\end{array}$ & 0.044 & 0.069 & 0.034 & 0.699 & 0.009 \\
\hline $\begin{array}{c}\text { Environmental } \\
\text { atmosphere } 2 \\
\end{array}$ & 0.375 & 0.019 & 0.253 & 0.470 & 0.029 \\
\hline $\begin{array}{c}\text { Environmental } \\
\text { atmosphere } 3\end{array}$ & 0.176 & -0.071 & 0.306 & 0.442 & 0.272 \\
\hline $\begin{array}{c}\text { Environmental } \\
\text { atmosphere } 4\end{array}$ & 0.294 & 0.008 & 0.240 & 0.658 & 0.157 \\
\hline $\begin{array}{c}\text { Environmental } \\
\text { atmosphere } 5 \\
\end{array}$ & 0.049 & 0.243 & -0.090 & 0.760 & 0.031 \\
\hline Emotional needs 1 & -0.027 & 0.007 & 0.244 & 0.308 & 0.592 \\
\hline Emotional needs 2 & 0.151 & 0.084 & -0.075 & 0.113 & 0.736 \\
\hline Emotional needs 3 & 0.236 & -0.022 & 0.189 & -0.113 & 0.707 \\
\hline Emotional needs 4 & 0.344 & -0.155 & 0.223 & -0.067 & 0.640 \\
\hline cumula & xplane & the tot & ance vo & $64.478 \%$ & \\
\hline
\end{tabular}

\section{Correlation Analysis}

Before making regression analysis, we need to verify the relationship between independent variables and dependent variables, that is, the relationship between influencing factors and cultural tourism decisions. This part uses the Pearson correlation analysis to test the relationship between the factors and the cultural tourism decision, which provides the necessary conditions for the subsequent regression analysis. 
Table 6. Summary of relevant analysis of influencing factors and cultural tourism decision-making

\begin{tabular}{|l|l|l|l|l|l|l|}
\hline variable & $\begin{array}{l}\text { Publicit-y } \\
\text { and } \\
\text { promoti-on }\end{array}$ & price level & $\begin{array}{l}\text { Cultural } \\
\text { connot-atio } \\
\text { n }\end{array}$ & $\begin{array}{l}\text { Environment } \\
\text {-al } \\
\text { atmosphere }\end{array}$ & $\begin{array}{l}\text { Affecti-o } \\
\text { n need }\end{array}$ & $\begin{array}{l}\text { Cultural } \\
\text { tourism } \\
\text { decision }\end{array}$ \\
\hline $\begin{array}{l}\text { Publicity and } \\
\text { promotion }\end{array}$ & 1 & $0.309^{* *}$ & $0.409^{* *}$ & $0.432^{* *}$ & $0.335^{* *}$ & $0.435^{* *}$ \\
\hline price level & $0.309^{* *}$ & 1 & $0.180^{* *}$ & $0.230^{* *}$ & 0.016 & $0.159^{*}$ \\
\hline $\begin{array}{l}\text { Cultural } \\
\text { connota-tion }\end{array}$ & $0.409^{* *}$ & $0.180^{* *}$ & 1 & $0.580^{* *}$ & $0.384^{* *}$ & $0.440^{* *}$ \\
\hline $\begin{array}{l}\text { Environ-mental } \\
\text { atmosph-ere }\end{array}$ & $0.432^{* *}$ & $0.230^{* *}$ & $0.580^{* *}$ & 1 & $0.379^{* *}$ & $0.391^{* *}$ \\
\hline affection need & $0.335^{* *}$ & 0.016 & $0.384^{* *}$ & $0.379^{* *}$ & 1 & $0.449^{* *}$ \\
\hline $\begin{array}{l}\text { Cultural } \\
\text { tourism decision }\end{array}$ & $0.435^{* *}$ & $0.159^{*}$ & $0.440^{* *}$ & $0.391^{* *}$ & $0.449^{* *}$ & 1 \\
\hline
\end{tabular}

According to Table 6, the four factors of publicity, cultural connotation, environmental atmosphere and emotional needs are significantly related to tourists' cultural tourism decision at 0.01 level. The factors of price level are significantly related to tourists' cultural tourism decision at 0.05 level, which shows that the five factors of publicity, price level, cultural connotation, environmental atmosphere and emotional demand are all related to tourists. The correlation coefficient between the factors of emotional demand and tourists' cultural tourism decision is 0.449 , which indicates that the correlation is the most significant. Secondly, the cultural connotation is 0.440 , the propaganda and promotion is 0.435 , the environmental atmosphere is 0.391 and the relative minimum correlation is the price level factor 0.159 .

\section{Regression Analysis}

Regression analysis can solve the problem is to find out the cause of the dependent variable variable and explaining, combined with this research, is to be judged by the regression analysis of influencing factors of tourism cultural tourism decision-making, and can influence how a detailed understanding of the influencing factors of tourist cultural tourism decision-making.

Table 7. Regression Analysis of influencing factors and tourist Cultural Tourism Decision-Making

\begin{tabular}{|l|l|l|l|l|l|l|l|}
\hline Model & R & R side & $\begin{array}{l}\text { Adjust the } \\
\text { R party }\end{array}$ & $\begin{array}{l}\text { Standard } \\
\text { estimation error }\end{array}$ & F & Sig. & $\begin{array}{l}\text { Durbin-Wats } \\
\text { on }\end{array}$ \\
\hline 1 & 0.582 & 0.539 & 0.322 & 0.82314839 & 20.7 & 0 & 1.809 \\
\hline
\end{tabular}

As can be seen from table 7 in the results of the regression analysis, The complex correlation coefficient $\mathrm{R}$ was 0.582 , and the adjusted decision coefficient $\mathrm{R} 2$ was 0.539 , indicating that the value of 53.9F can explain the variation of dependent variables was 20.700, and its significant probability was 0.000 . The regression effect was very significant (Durbin-Watson coefficient 1.809 ). From 1.5 to 2.5 and close to 2, it shows that there is no sequence correlation between different numbers of sample values and error terms.

Table 8. Regression analysis of influencing factors and tourists' cultural tourism decision

\begin{tabular}{|c|c|c|c|c|c|c|}
\hline Model & \multicolumn{4}{|c|}{$\begin{array}{c}\text { Non-standardized coefficient } \\
\text { Standard coefficient }\end{array}$} & t & Sig. \\
\hline & explanatory variable & $\mathrm{B}$ & stand-ard error & trial versi-on & & \\
\hline & constant (quantity) & 0.000 & 0.057 & & .000 & 1.000 \\
\hline & affection need & 0.272 & 0.065 & 0.272 & 4.193 & .000 \\
\hline & Publicity and promotion & 0.222 & 0.068 & 0.222 & 3.265 & .001 \\
\hline & Cultural connotation & 0.199 & 0.073 & 0.199 & 2.719 & .007 \\
\hline & Environmental atmosphere & 0.069 & 0.074 & 0.069 & 0.927 & .000 \\
\hline & price level & 0.034 & 0.061 & 0.034 & 0.556 & .009 \\
\hline
\end{tabular}

b. Dependent variable: cultural Tourism Decision-making

Table 8 shows that there are five independent variables, that is, promotion, price level and cultural connotation, combined with the results of relevant analysis. Environmental atmosphere and 
emotional needs enter the final regression equation. The significant probability of these independent variables is less than 0.01 , which indicates that these factors have significant regression effect on tourist cultural tourism decision. In the final regression equation, The standard regression coefficient of emotional demand factor is 0.272 , which shows that its influence weight on tourist's cultural tourism decision ranked first. The second is the promotion factor 0.222 , the cultural connotation 0.199 , the environment and atmosphere 0.069 , and the price level 0.034 , relatively the least, the second is the promotion factor $(0.222 \%)$, the cultural connotation factor $(0.199 \%)$, the environmental atmosphere factor $(0.069 \%)$ and the price level factor $(0.034)$. The final standard regression equation can be obtained: tourist cultural tourism decision making $0.272 *$ emotional demand $0.222 *$ propaganda and promotion $0.199 *$ cultural connotation $0.069 *$ Environmental atmosphere $0.034 *$ Price level R2O 0.539.

\section{Data Analysis Results}

By summing up the above analysis results, the following results can be obtained so that the factors and tourist cultural tourism decisions can be more clearly presented.

- There are five influencing factors for tourists' cultural tourism decision, which are publicity, price level and cultural connotation.Environmental atmosphere, emotional needs.

- The influence degree of the above five influencing factors on tourist's cultural tourism decision is as follows: emotional demand, Promotion, cultural connotation, environmental atmosphere and price level. The standard regression equation is: tourist cultural tourism decision=Affective demand 0.222 * publicity and promotion of $0.199 *$ Cultural connotation $0.069 *$ Environmental atmosphere 0.034 * Price level $\quad\left(\mathrm{R}^{2}=0.539\right)$.

\section{Enlightenment of Research Management}

The data analysis of this study shows that there are five factors that influence the decision making of tourist cultural tourism, among which emotional needs are influenced.The biggest weight is 0.272 , the propaganda and promotion is 0.222 , the third is cultural connotation, the environmental atmosphere is 4th and 0.069, and the price level is the lowest. Therefore, the countermeasures and suggestions for promoting tourists to make cultural tourism decisions should be put forward from five aspects. The management implications of this study can be summarized as follows:

\section{Introducing the Emotional value Demands of Cultural Tourism}

1) to develop a cultural tourism project with the guidance of tourists' emotional needs. Cultural tourism should not be simply landscape viewing, cultural works display, etc. It should be combined with the intrinsic emotional needs of tourists, mobilize five senses and telepathy, endow tourism projects with specific cultural connotations, and develop a series of cultural tourism projects that experience innovation. It makes the dual participation of physiology and psychology in the process of tourism, including the touch of senses and thoughts, and can make tourists deeply realize the charm of cultural tourism innovation project, and thus obtain the satisfaction of spirit and psychology.

2) based on the emotional needs of tourists, the design of cultural tourism products containing emotional elements is designed.Cultural tourism commodities are the extension of cultural tourism experience, most of them like emotional things. Therefore, when designing cultural tourism commodities, the appearance of goods, packaging design, In order to meet the psychological and emotional demands of tourists in the aspects of functional needs and operational details, cultural tourism commodities can touch the tourists' hearts in terms of perspective, behavior and soul, and make them emotional. Extend the beautiful experience of cultural tourism to life.

\section{Strengthening the Publicity and Promotion of Cultural Tourism}

1) Cultural tourism spots should closely focus on the cultural characteristics of the scenic spots, organize and carry out cultural tourism promotion activities, such as cultural tourism trade fairs, exhibitions, and so on, so as to demonstrate the achievements of cultural tourism brand building. 
Continue to expand the influence and appeal of cultural tourism brands. On the other hand, we should put an end to all vulgar propaganda and actively establish a positive image of cultural tourism scenic spots.

2) The travel agency should make great efforts to create the fine line of cultural tourism, take the cultural connotation as the bright spot, take the reasonable itinerary as the selling point, continuously consummate the structure of cultural tourism products according to the tourists' emotional demand, and base itself on the reality while packing hype. Avoid false flattery and win the trust of tourists.

3) The Internet is the primary source of information for cultural tourists. Travel agencies and cultural tourism scenic spots should make good use of this media means to broaden the channels of network propaganda on the basis of the previous promotion of television, radio and newspapers. For example, we can set up a detailed cultural tourism introduction module on the official website of scenic spot and the home page of travel agency website, so as to improve the popularity of all kinds of cultural tourism and make cultural tourism predominate in the fierce competition of the whole tourism industry.

\section{Excavate and Promote the Cultural Connotation of Cultural Tourism Scenic spot}

1) Cultural tourism scenic spots should have a general layout so that the cultural image of foreign countries can be carried on with the local historical context. Deeply study the local historical origin, excavate the relevant historical allusions, legends, historical anecdotes, or highlight the cultural characteristics of the folk festival activities as the cultural connotation of the scenic area carrier.

2) Integrate cultural elements into various cultural tourism projects, start with "eat, live, travel, travel, buy and entertain", strengthen the packaging of the cultural connotations of various products in cultural tourism scenic spots, and always closely surround the essence of local culture. The cultural nature of cultural tourism is given to all aspects of cultural tourism projects in order to meet the cultural needs of tourists.

3) Further strengthen the cultural brand shaping of cultural tourism scenic spots, create cultural tourism boutique and constantly open up new channels of promotion.For cultural attractions, tourist commodities, folk customs and excellent songs and dances can concentrate manpower, material resources, financial resources, carry out professional packaging and promotion, and take the road of industrialization. Efforts should be made to cultivate infectious and popular tourist brands that are popular among cultural tourists.

\section{Creating a Good Atmosphere of Cultural Tourism Environment}

1) The cultural tourist destination must base itself on the local folklore and local customs, establish its own tourism cultural theme, and form a cultural atmosphere with local characteristics around the theme.In the construction of cultural tourism sites, we should consider the overall cultural characteristics, not only pay attention to the problems of traditional dress, architectural style and lifestyle, but also reflect the local cultural characteristics in many aspects. Let tourists fully feel the unique cultural atmosphere.

2) Clean and tidy, pleasing to the eye is the first impression given to tourists by tourist destinations. Therefore, it is necessary to strengthen the protection of the ecological environment, create a high-quality tourist sanitation environment, and establish a beautiful, elegant, and culturally rich hospitality place. Let tourists have a wonderful experience.

3) The service level and service quality seriously affect the tourists' willingness to revisit and recommend to the outside world. The government and other relevant departments of the cultural tourism destination should pay more attention to this. In order to improve the level and quality of service, tourists will be fully respected in the process of cultural tourism so as to enhance their satisfaction and loyalty.

\section{Perfecting the Price Formation Mechanism of Cultural Tourism Market}

1) To establish a reasonable mechanism for the formation of ticket prices in cultural tourism scenic spots, under the premise of adhering to the principle of government pricing, to make clear the source 
of income and distribution of tickets in cultural tourism scenic spots, to accept social supervision actively, and to establish an optimized price hearing mechanism. Ensure the public's right to know and participate, and let the scenic spot return to its commonweal attribute.

2) Make relevant laws and regulations, strictly control the commodity, dining and accommodation price of cultural tourist spot, increase the punishment of service personnel and service industry, deceive the customer to kill the guest, and maintain the good faith management of the scenic spot.

3) Government tourism departments and price management departments should give full play to the macro-control role, supervise the group prices of travel agencies in real time, and give timely feedback to the public on the results of supervision and verification, so as to expose the list of travel agencies that violate the price mechanism. We will standardize the operation of travel agencies.

\section{Acknowledgement}

Wuhan Polytechnic University in 2018, the university set up a scientific research project (xsky2018082).

\section{References}

[1] Xu Liyong.A brief analysis of the three trends of cultural industry planning in the 13th Five-Year Plan .Humanities: 10: 36-38.

[2] Guo Yajun. Study on tourists' Decision-making behavior .A Ph.D. thesis of Northwestern University: 6: 24-27

[3] Couture A, Arcand M, Sénéca S, et al. The influence of tourism innovativeness on online consumer behavior. Journal of Travel Research, 2015,54(1):66-79

[4] Ponte B, Elena Carvajal-Trujillo E, Escobar-Rodríguez T. Influence of trust and perceived value on the intention to purchase travel online: Integrating the effects of assurance on trust antecedents Enrique. Tourism Management, 2015,47:286-302.

[5] Wei Baoxiang, Gongshing.A study on the influence of Internet Information on tourists' Decision-making: a Comparative study at Home and abroad. Humanistic Geography: 05: 10-13

[6] Sanglinxi, Wang Liangju, Zhao Tengfei .Journal of Chongqing Institute of Science and Technology (Social Science Edition), 01U: 33-36

[7] Pearce, D. G. Tourism Today: A Geographical Analysis. Harlow: Longman, 1987, pp.112-144

[8] Xu Chunxiao, Wang Jie, Xu Jilan, Analysis of the rules of decision making of Changsha Citizen Culture Tourism .Journal of Central South University of Forestry Science and Technology (Social Science Edition)

[9] Lu Jindai, SPSS for Windows statistical analysis. Beijing: electronic Industry Press, 2000, pp.341.

[10] Liu Dashan. Perfect the pricing mechanism of scenic spots and break the dilemma of "three years must rise". Nanjing Daily, 2015-8-24A6 